\title{
Physicians' health practices strongly influence patient health practices
}

\author{
${ }^{1}$ EB Oberg, ${ }^{2}$ E Frank \\ ${ }^{1}$ Senior Fellow, School of Public Health and Community Medicine, University of Washington, Seattle, USA; ${ }^{2}$ Professor and Canada Research \\ Chair, School of Population and Public Health and Department of Family Practice in the Faculty of Medicine, University of British Columbia, \\ Vancouver, Canada
}

KEYWORDS Counselling, health promotion, physician health, prevention, role modelling

DECLARATION OF INTERESTS No conflict of interests declared.
Published online December 2009

Correspondence to E Frank, School of Population and Public Health and Department of Family Practice, University of British Columbia, 5804 Fairview Ave., Vancouver, BC V6T IZ3, Canada

e-mail erica.frank@ubc.ca
Physicians who practise healthy habits play a key role by helping their patients to adopt healthy lifestyles for primary prevention of chronic diseases. The health of general practitioners (GPs) is important because they serve as health role models and because they are more likely to counsel their patients about health behaviour change if they practise healthy habits themselves. One of the strongest predictors of health promotion counselling by primary care physicians is practising a healthful behaviour oneself - it is clear that many physicians report difficulty counselling patients about behaviours they themselves do not practise. ${ }^{1,2}$

Health promotion counselling by providers is more effective than outsourcing counselling to a specialist or health coach, in part because patients view GPs as the most trusted source of health information. Since physicians are key health role models and advisors who often meet with patients during potentially impressionable times, their own health behaviours may affect their ability to engage their patients in healthful behaviours. ${ }^{3}$ In fact, the majority of people cite their physician as their primary source of information regarding healthy lifestyle decisions and are more likely to adopt a healthy behaviour when their physician recommends it. ${ }^{4}$

Currently, GPs in the UK report spending an average $16 \%$ of practice time on prevention, and $79 \%$ report educating patients about lifestyle risk 'most' or 'all of the time'. ${ }^{5}$ This is superior to US estimates but is still not optimal. Data from the 2000 US National Ambulatory Medical Care Survey revealed that only $15.7 \%$ of office visits to primary care providers included health counselling on diet, physical activity or stress reduction. ${ }^{6}$ While this is worryingly low, barriers to increasing counselling rates are significant. One identified barrier to greater health promotion counselling is that providers report difficulty counselling patients on behaviours that they struggle with themselves. ${ }^{2}$ Combined with the other main barrier that UK GPs report - a lack of time ${ }^{7}$ - this raises concerns about the new 48-hour working week limitations, as these changes may affect both personal and professional health promotion activities. It was recently determined that the average primary care provider would need 7.4 hours of each day in order to meet all the preventive services' recommendations for all patients - exclusive of health promotion counselling for chronic disease states! ${ }^{8}$ Clearly, GPs will struggle to provide optimal care, unless additional changes to the healthcare delivery system are made.

Yet these findings also underscore the importance of GPs' influence as role models of healthy behaviours, as 'practising what we preach' may be an effective and efficient strategy to increase health promotion activities among patients. Practising healthy behaviours oneself is strongly correlated with counselling patients on that behaviour.' This holds true regardless of the provider's actual health status. In fact, physicians who were attempting to improve poor habits counselled patients significantly more often than physicians who were not trying to change their own behaviour.' Correlations between personal practices and counselling rates have been found consistently across prevention and health promotion topics. ${ }^{1,10}$ For prevention and health promotion topics ranging from dietary fat intake, sunscreen use, mammography screening, physical activity, smoking, alcohol use and others, we have demonstrated strong personal-clinical correlations. The impact of personal practices has also been demonstrated in observational conditions with medical students and standardised patient models: even just being encouraged to have healthy personal practices increases medical students' rates of health promotion counselling." 
Importantly for busy GPs, we have found that simply talking to your patients about your personal practices improves your health promotion delivery. Providers who disclose their healthy personal health practices are perceived as more credible and motivating. ${ }^{3}$ This has been shown by others as well: rates of prevention counselling increase and patients become more receptive to health promotion counselling from physicians who demonstrate healthy behaviours themselves. ${ }^{12}$ Kreuter et al. found that when physicians discussed health promotion with their patients, even when the patients had already received printed materials on the same topic, those that were directly counselled by their physician were $35-55 \%$ more likely to quit smoking, make changes to their diet and begin exercising compared with those who only received literature encouraging the same thing. ${ }^{13}$

Rates of health promotion counselling among physicians can be increased through provider-centred health promotion. In our four-year controlled trial that addressed lifestyle behaviours over the course of medical school, student physicians made improvements in their personal health practices, and self-reported counselling on the topics improved as well. By senior year, control males reported twice the tobacco use reported by males in the intervention ( $43 \%$ vs $22 \%, p=0.02$ ), although they had previously reported very similar levels (31\% vs $29 \%$, $p=0.8$ ). Diet and exercise counselling were strongly positively related to the intervention, alcohol was inversely related to the intervention and tobacco practices showed modest effect. ${ }^{14}$

Physicians can positively influence patients' health habits by counselling them about prevention and healthpromoting behaviours. Physician counselling is strongly related to one's own health practices, so addressing providers' own health behaviours is key to substantially increasing health promotion counselling in general practice. Providers benefit from interventions that help them adopt healthier lifestyles - this benefit is not only for their personal health, but for the health of their entire patient population, which is likely to profit from more efficient and effective health promotion counselling.

\section{REFERENCES}

I Frank E. Physician health and patient care. JAMA 2004; 29I:637. doi:I0.100I/jama.29I.5.637

2 Vickers KS, Kircher KJ, Smith MD et al. Health behavior counseling in primary care: provider-reported rate and confidence. Fam Med 2007; 39:730-5.

3 Frank E, Breyan J, Elon L. Physician disclosure of healthy personal behaviors improves credibility and ability to motivate. Arch Fam Med 2000; 9:287-90. doi:10.100I/archfami.9.3.287

4 Abramson S, Stein J, Schaufele $M$ et al. Personal exercise habits and counseling practices of primary care physicians: a national survey. Clin J Sport Med 2000; 10:40-8. doi: 10.1097/00042752-20000100000008

5 McAvoy BR, Kaner EF, Lock CA et al. Our healthier nation: are general practitioners willing and able to deliver? A survey of attitudes to and involvement in health promotion and lifestyle counselling. Br J Gen Pract 1999; 49:187-90.

6 Ma J, Urizar GG, Alehegn $T$ et al. Diet and physical activity counseling during ambulatory care visits in the United States. Prev Med 2004; 39:8I5-22. doi:I0.1016/j.ypmed.2004.03.006

7 Douglas F, Torrance N, van Teijlingen E et al. Primary care staff's views and experiences related to routinely advising patients about physical activity. A questionnaire survey. BMC Public Health 2006; 6:138. doi:I0.1/86/I47|-2458-6-138
8 Yarnall KS, Pollak KI, Ostbye T et al. Primary care: is there enough time for prevention? Am J Pub Health 2003; 93:635-4I. doi:I 0.2105/ AJPH.93.4.635

9 Lewis CE, Wells KB,Ware J. A model for predicting the counseling practices of physicians.J Gen Intern Med 1986; I: 14-9. doi: I0.1007/ BF02596319

10 Frank E, Segura C, Shen $\mathrm{H}$ et al. Predictors of Canadian physicians' prevention counseling practices. CMAJ 2009; in review.

II Frank E, Carrera JS, Elon L et al. Predictors of US medical students' prevention counseling practices. Prev Med 2007; 44:76-81. doi:10.1016/j.ypmed.2006.07.018

12 Rogers LQ, Gutin B, Humphries MC et al. Evaluation of internal medicine residents as exercise role models and associations with self-reported counseling behavior, confidence, and perceived success. Teach Learn Med 2006; I8:2I5-2I. doi:I0.1207/s I53280I5tlmI803_5

13 Kreuter MW, Chheda SG, Bull FC. How does physician advice influence patient behavior? Evidence for a priming effect. Arch Fam Med 2000; 9:426-33. doi:10.1001/archfami.9.5.426

I4 Frank E, Elon L, Hertzberg V. A quantitative assessment of a 4-year intervention that improved patient counseling through improving medical student health. MedGenMed 2007; 9:58. 